\title{
STATIC PRESSURE DROP IN LAYERS OF CASTOR BEAN GRAINS
}

\author{
André L. D. Goneli ${ }^{1 *}$, Paulo C. Corrêa ${ }^{2}$, Acácio Figueiredo Neto ${ }^{3}$, Michele R. H. Kirsch ${ }^{1}$, \\ Fernando M. Botelho ${ }^{4}$
}

${ }^{1 *}$ Corresponding author. Federal University of Grande Dourados/ Dourados - MS, Brazil.
E-mail: andregoneli@ufgd.edu.br | ORCID ID: https://orcid.org/0000-0001-9963-3497

\section{KEYWORDS}

bulk density, load loss, porosity, Ricinus communis L., moisture content

\begin{abstract}
Knowledge regarding the static pressure drop in granular layers is of fundamental importance in the development of efficient drying and aeration projects of agricultural products. Thus, the objective of this study was to evaluate the effects of impurity contents on the static pressure drop in different bed depth of castor bean grains, as well as modify the mathematical models per the obtained experimental data and select the model that best represents this phenomenon. First, impurities in castor bean grains of the Guarani variety were eliminated and $6 \%$ of the moisture content (dry basis) was retained. The coarse impurity contents were obtained with $2 \%, 4 \%$, and $6 \%$ of mass addition. The pressure drop in different bed depth of clean and impure castor bean grains were determined using an experimental determination equipment of pressure drop in bed depth with an airflow rate ranging $0.2-1.0 \mathrm{~m}^{3} \mathrm{~s}^{-1} \mathrm{~m}^{-2}$. The pressure drop linearly increases with an increase in the depth of the grain layer, and the increase in the airflow rate leads to an increased pressure drop in the castor bean grains layer. The impurity contents increase causes a reduction in pressure drop. The models that best represent castor beans grains pressure drop experimental data, without and with impurities, are Hukill \& Ives (1955) and Nimkar \& Chattopadhyay (2002), respectively.
\end{abstract}

\section{INTRODUCTION}

Castor bean (Ricinus communis L.) is an oil plant having enormous economic and social significance, which can be found in several regions of Brazil, generating employment and income owing to its numerous application possibilities in the industrial area, in addition to its energy potential prospects in biodiesel production (Rampadarath \& Puchooa, 2016; Vasconcelos et al., 2017). However, with the increasing demand for this crop, many producers are compelled to apply methods that were traditionally used for the preservation of grains and cereals, thus rending it essential to study post-harvest stages of castor bean grains to preserve their physiological characteristics for long periods of time avoid grain deterioration resulting from their biological activity.

Among grain preprocessing techniques, drying is most commonly used to remove excess water in the product through evaporation. Such removal processes involve a complex process including the simultaneous transfer of heat and mass between the drying air and the product to be dried (Goneli et al., 2014). In this process, the wet product is placed in contact with hot air so that the heat supply promotes the evaporation of water contained in the material.

Another technique that also utilizes air is aeration; however, in this process, air is only used to homogenize and reduce the temperature of the grain mass during the storage stage, thereby minimizing moisture migration and avoiding temperature oscillations caused by the emergence of insects and microflora, as well as preserving the quality of the stored product (Vasconcellos, 2014).

Therefore, many processes need an air distribution system, usually forced ventilation systems, the function of which is to distribute air as homogeneously as possible to improve the efficiency of the process and the equipment used. In projects involving such systems, the resistance that the product offers to air passage must be known, as

\footnotetext{
${ }^{1}$ Federal University of Grande Dourados/ Dourados - MS, Brazil

${ }^{2}$ Federal University of Viçosa/ Viçosa - MG, Brazil.

${ }^{3}$ Federal University of Vale do São Francisco/ Petrolina - PE, Brazil.

${ }^{4}$ Federal University of Mato Grosso/ Sinop - MT, Brazil.
} 
well as the airflow required in the process (Teixeira et al., 2016; Faoro et al., 2014).

When air is forced to pass through a layer of granular product, any resistance will lead to a compression effort between the molecules of the air; this is called resistance to airflow or pressure drop. This pressure must have sufficient intensity to overcome the resistance imposed on the flow, which are as follows: the roughness of the internal surfaces of the ducts, the perforated sheet of the distribution ducts, the height of the grain column, the product, height, and compaction of the grain mass, and the impurity contents in the product (Silva, 2014).

Pressure drop in the grain layers is a property that has received considerable attention from professionals working in the field of preprocessing and storage of agricultural products because of its effect on the analysis of airflow distribution uniformity and determination of the amount of energy that the system movement requires to transfer into the air so that it can overcome the resistance imposed on the flow.

Therefore, knowledge regarding the pressure drop is vital for the efficient design of drying and aeration systems of agricultural products. Moreover, the basic principles of air movement should be considered to ensure that the entire granular mass is evenly traversed by air because inappropriate sizing of air movement systems can cause fungus development in areas with low air velocity and over-drying of grains in areas with high air velocity.

Hence, this study aims to evaluate the influence of coarse impurity contents on the static pressure drop in different bed depth of castor bean grains, as well as modify the mathematical models to the obtained experimental

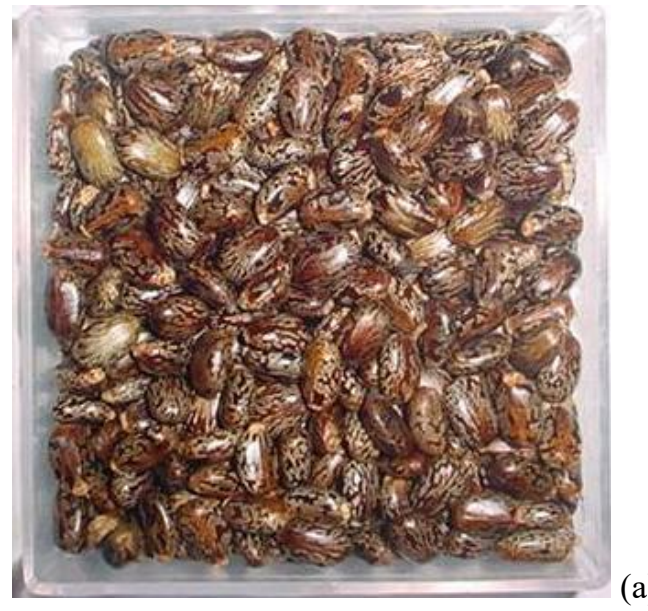

data obtained and select the model that best represents this phenomenon.

\section{MATERIAL AND METHODS}

Castor bean grains of the Guarani variety were used from commercial plantations obtained from the city of Várzea da Palma, Minas Gerais. The fruits were harvested in the middle portions of the first set of the plantation.

In the field, the fruits were homogenized and packaged in low-density polypropylene bags and transported to the Laboratory of Storage and Processing of Plant Products of the Department of Agricultural Engineering at the Federal University of Viçosa, Viçosa$\mathrm{MG}$, for analyses.

After being harvested with a moisture content of approximately $11 \%$ dry base (b.s.), the fruits were threshed in a threshing machine adapted to the castor bean crop. Subsequently, the grains were sieved to remove the impurities and foreign matter from the mass. The moisture content of the grains, after harvesting and processing, was approximately $6 \%$ b.s.

To analyze the effect of coarse impurities on the static pressure, unpeeled grains and dried fruit straw were used, derived from the processing of castor bean grains. Figure 1 shows the clean grain samples (without impurities) and the impurities used in this work. Clean grains were assumed to have $0 \%$ impurities, the remaining percentages were obtained by adding $2 \%, 4 \%$, and $6 \%$ of material mass to the total granular mass deposited in each column.

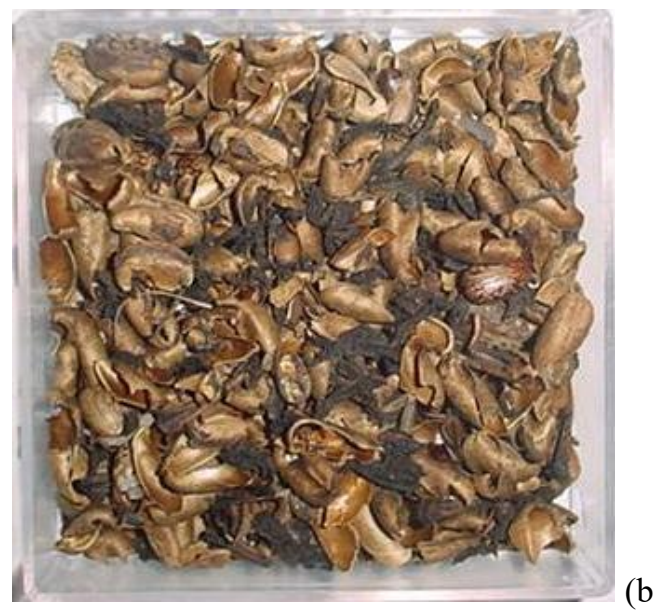

FIGURE 1. Samples of castor bean grains without impurities (a) and coarse impurities from grain processing (b).

Static pressure drop tests were conducted on an experimental determination equipment of pressure drop in bed depth shown in Figure 2. The structure of the equipment (Figure 2) has transition elements (expansions), plenum, and profile for grain accommodation in a thick layer. The plenum chamber was designed to allow sufficient air distribution, while transition elements or expansions were used to standardize the flow of air passing through the grain layer. For each treatment, pressure drop was measured $(n=3)$ for different airflow rates. 


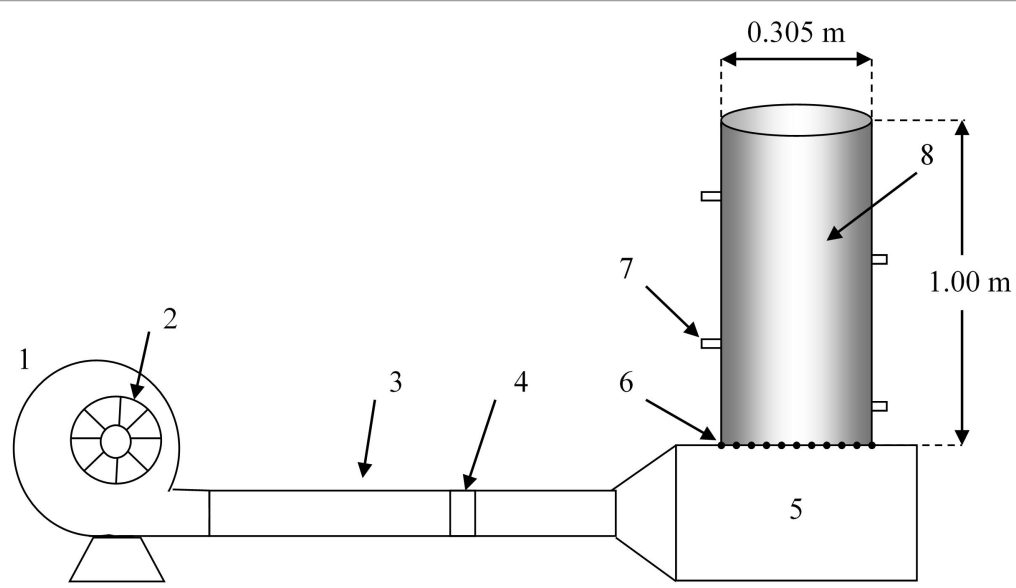

FIGURE 2. Apparatus for measuring pressure drop in bed depth.

in which:

1 - Straight-bladed centrifugal fan: Motor from $0.552 \mathrm{~kW}$ at $3460 \mathrm{rpm}$;

2 - Diaphragm for varying the airflow in the grain column;

3 - Transition tube;

4 - Airflow homogenizer;

5 - Plenum for pressure homogenization;

6 - Perforated floor constructed with a thin square mesh screen on a perforated steel sheet fixed at the bottom of the column;

7 - Static pressure outlet;

8 - Circular column.

At each point, pressure drop was measured using two differential pressure gauges of inclined tubes and a Ugauge; different manometer types were used to ensure the reliability and accuracy of the readings. The column was filled with the free-falling product from a funnel located 1 $\mathrm{m}$ above the bottom of the column.

The opening of the diaphragm installed in the air intake of the fan was subjected to variation for obtaining different airflow rates, which in this work were in the range of 0.2 to $1.0 \mathrm{~m}^{3} \mathrm{~s}^{-1} \mathrm{~m}^{-2}$. The layer thicknesses of castor bean grains used to collect static pressure ranged from 0.06 to $0.65 \mathrm{~m}$.

Next, five samples per treatment (with and without coarse impurities), weighing approximately $2 \mathrm{~kg}$ each, were considered for the physical characterization of castor bean grains. The water levels of the product were determined using the gravimetric method in a greenhouse with forced air circulation at $105 \pm 1{ }^{\circ} \mathrm{C}$ for 24 hours in two repetitions (Brasil, 2009).

The bulk density was calculated as the ratio of the mass to grain volume, and it was measured in a graduated cylinder with a volume of $1000 \mathrm{~mL}$. The product was packed in the container, and the grain mass was measured using an analytical balance with a resolution of $0.01 \mathrm{~g}$.

The intergranular porosity of grain masses was measured using an electronic air comparison pycnometer, equipped with an automatic air injection device and pressure control, according to the process described by Day, cited by Mohsenin (1986).

By associating the pressure drop per unit depth to the airflow rates, the experimental data (without and with different percentages of impurities) were adjusted to the mathematical models shown in Table 1, which relate to the pressure drop of agricultural products with different impurity contents.

TABLE 1. Models used to estimate the pressure drop in castor bean grain layer with different impurity contents.

\section{Models}

Shedd (1951)

Hukill \& Ives (1955)

Hunter (1983)

Linear

Giner \& Deinisienia (1996)

Guimarães (1998)

Haque (1978)

Nimkar \& Chattopadhyay (2002) modified by the authors Equations

$$
\begin{aligned}
& \Delta \mathrm{PL}=\mathrm{aQ} \mathrm{Q}^{\mathrm{b}} \\
& \Delta \mathrm{PL}=\frac{\mathrm{aQ} \mathrm{Q}^{2}}{\ln \left(1+\mathrm{b}^{\mathrm{Q}}\right)} \\
& \Delta \mathrm{PL}=\mathrm{aQ}+\mathrm{bQ}^{2} \\
& \Delta \mathrm{PL}=\mathrm{a}+\mathrm{bQ} \\
& \Delta \mathrm{PL}=(\mathrm{a}+\mathrm{bI}) \mathrm{Q}(1+3 \mathrm{Q}) \\
& \Delta \mathrm{PL}=\mathrm{aQ} \mathrm{Q}^{\mathrm{b}}+\mathrm{cI} \\
& \Delta \mathrm{PL}=\mathrm{aQ}+\mathrm{bQ}^{2}+\mathrm{cQI} \\
& \Delta \mathrm{PL}=\mathrm{aQ}+\mathrm{bQ}^{2}+\mathrm{cQI}+\mathrm{d} \rho_{\mathrm{a}} \mathrm{Q}
\end{aligned}
$$


in which:

$\Delta \mathrm{PL}$ - pressure drop per unit depth, $\mathrm{Pa} \mathrm{m}^{-1}$;

$\mathrm{Q}$ - airflow rate, $\mathrm{m}^{3} \mathrm{~s}^{-1} \mathrm{~m}^{-2}$;

$\mathrm{a}, \mathrm{b}$ - regression parameters that depend on the product;

I - coarse impurity contents, decimal;

$\rho a$ - bulk density, $\mathrm{kg} \mathrm{m}^{-3}$,

c, $\mathrm{d}$ - parameters that depend on the product.

The model proposed by Nimkar \& Chattopadhyay (2002) was modified by the authors of this study by replacing the variation factor of the moisture content by including variable factor impurity content. Such modification was more appropriate for data collection, thus ensuring a more suitable model for future use.

For the adjustment of mathematical models, linear and nonlinear regression analyses were conducted using the Gauss-Newton method. Models were selected considering the magnitude of the standard error of estimate (SSE), mean relative error (MRE), and coefficient of determination $\left(\mathrm{R}^{2}\right)$. The mean relative error value of less than $10 \%$ was a criterion for model selection (Mohapatra \& Rao, 2005).

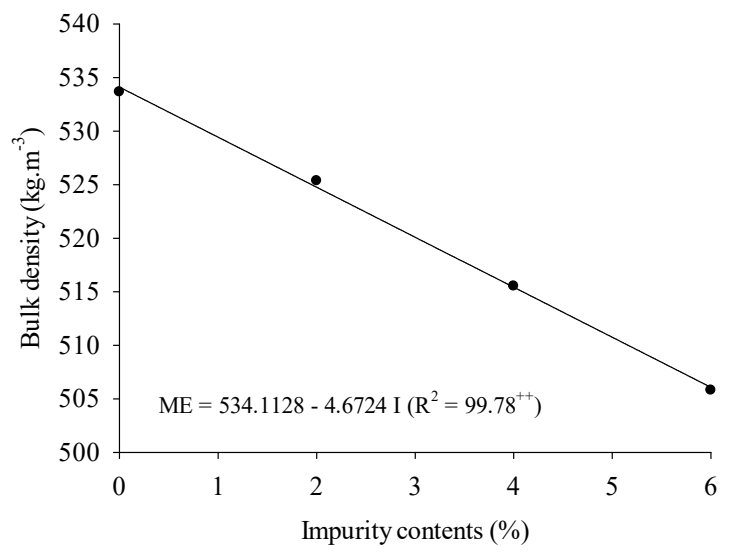

(a)
For each model, standard error of estimate and mean relative error were calculated using eqs (9) and (10).

$$
\begin{aligned}
& \mathrm{SSE}=\sqrt{\frac{\sum_{\mathrm{i}=1}^{\mathrm{N}}\left(\mathrm{MR}_{\mathrm{exp}}-\mathrm{MR}_{\text {pre }}\right)^{2}}{\mathrm{D}_{\mathrm{f}}}} \\
& \mathrm{MRE}=\frac{100}{\mathrm{~N}} \sum_{\mathrm{i}=1}^{\mathrm{N}}\left|\frac{\mathrm{MR}_{\mathrm{exp}}-\mathrm{MR}_{\mathrm{pre}}}{\mathrm{MR}_{\mathrm{exp}}}\right|
\end{aligned}
$$

in which:

$$
\begin{aligned}
& \mathrm{N} \text { - number of experimental observations; } \\
& \mathrm{MR}_{\mathrm{exp}} \text { - experimental moisture ratio; } \\
& \mathrm{MR}_{\mathrm{pre}} \text { - predicte moisture ratio; } \\
& \mathrm{D}_{\mathrm{f}} \text { - degrees of freedom. }
\end{aligned}
$$

\section{RESULTS AND DISCUSSION}

Coarse impurities, typical for castor bean fruit processing, influence the bulk density and porosity of castor bean grains (Figure 3).

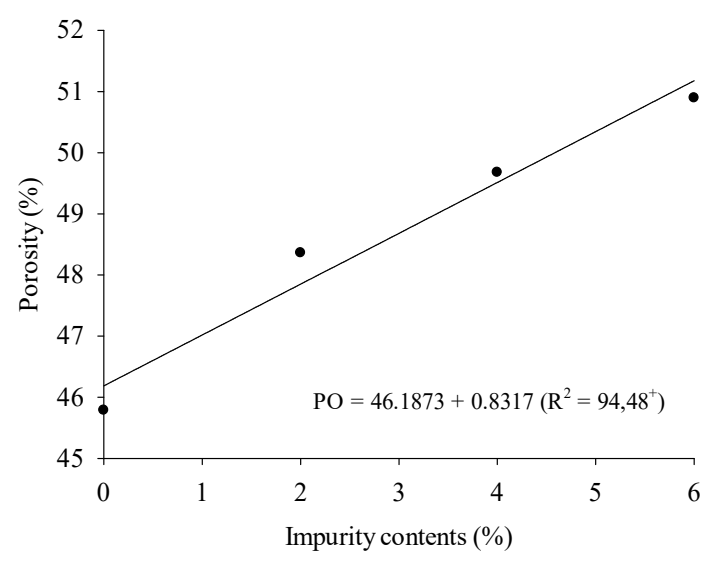

(b)

FIGURE 3. Values of bulk density in $\mathrm{kg} \mathrm{m}^{-3}$ (a) and porosity in $\%$ (b) of castor bean grains as a function of different impurity contents. $\left({ }^{++}\right.$significant to $1 \%$ probability and ${ }^{+}$significant to $5 \%$ probability, F-test).

The increased content of coarse impurities reduces the bulk density and increases the porosity of castor bean grains, as impurities occupy the void space in the product mass. Similar results were obtained by Gratão et al. (2013) and Botelho et al. (2019) working with quinoa beans and soybeans and husk rice, respectively.

Moreover, the linear models were satisfactorily modified to the observed data, demonstrating high values of the coefficient of determination and the significance level of regressions (F-test).

The bulk density and porosity are vital physical properties to quantify the resistance that a mass of grains imposed on the flow of air is usually dependent on the moisture content of the product and the presence of impurities (Botelho et al., 2018; Mata \& Duarte, 2002). Working with parchment coffee, Agullo \& Marenya (2005) concluded that the relationship between the bulk density and the pressure drop is directly proportional, i.e., the greater the bulk density of the grain mass, the greater the resistance imposed by these to the passage of airflow.

The pressure drop linearly increases with increasing bed depth of castor bean grains (Figure 4). Furthermore, for the same bed depth value, pressure drop values increased with the increasing airflow rate. These results are similar to those found by Kenghe et al. (2011), Figueiredo Neto et al. (2012), Gratão et al. (2013) e Teixeira et al. (2015), and Faoro et al. (2017). 


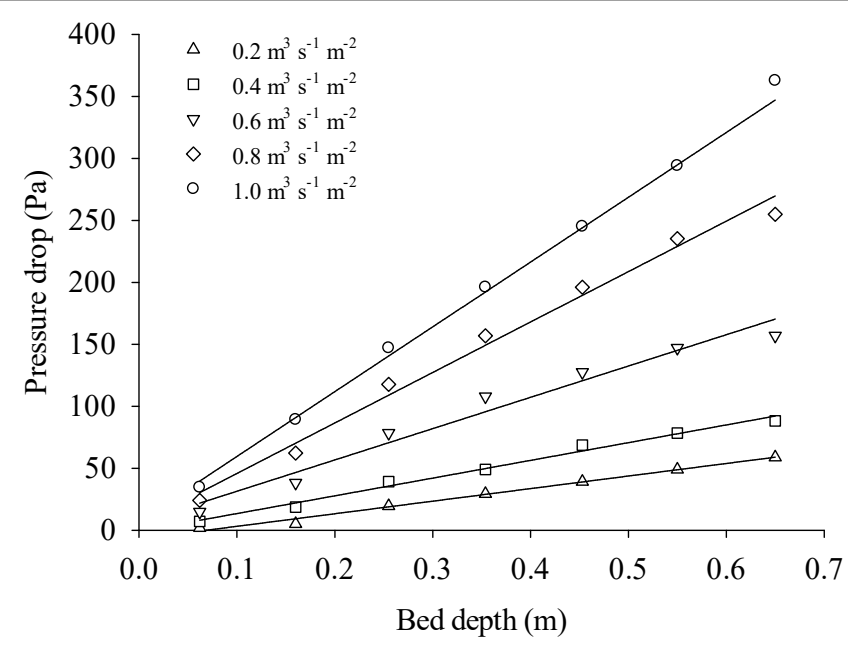

FIGURE 4. Effect of bed depth and airflow rate on pressure drop for castor bean grains with moisture content of $6 \%$ b.s.

Table 2 lists the model parameters that were modified according to the pressure drop data $\left(\mathrm{Pa} \mathrm{m}^{-1}\right)$ of castor bean grains and that were free of impurities, with moisture content of $6 \%$ b.s., depending on airflow rate $\left(\mathrm{m}^{3} \mathrm{~s}^{-1} \mathrm{~m}^{-2}\right)$, as well as their respective values of standard error of estimate (SSE), mean relative error (MRE), and coefficient of determination $\left(R^{2}\right)$.

TABLE 2. Estimates of pressure drop model parameters for castor bean grains for the product that was free of impurities.

\begin{tabular}{|c|c|c|c|c|c|}
\hline Models & & ameters & SSE & MRE (\%) & $\mathrm{R}^{2}(\%)$ \\
\hline Shedd (1951) & $\begin{array}{l}a= \\
b=\end{array}$ & $\begin{array}{c}554,8726 \\
1,3169\end{array}$ & 24,21 & 10,73 & $99,19^{++}$ \\
\hline Hukill \& Ives (1955) & $\begin{array}{l}a= \\
b=\end{array}$ & $\begin{array}{c}612,3868 \\
1,9977\end{array}$ & 24,27 & 9,51 & $99,18^{++}$ \\
\hline Hunter (1983) & $\begin{array}{l}a= \\
b=\end{array}$ & $\begin{array}{l}326,1294 \\
232,1928\end{array}$ & 24,50 & 9,27 & $99,15^{++}$ \\
\hline Linear & $\begin{array}{l}a= \\
b=\end{array}$ & $\begin{array}{l}-65,4203 \\
605,3149\end{array}$ & 29,19 & 14,84 & $98,37^{++}$ \\
\hline
\end{tabular}

${ }^{++}$Significant at $1 \%$ probability (F-test).

Among the four models tested, Hukill \& Ives (1955) and Hunter (1983) models yielded the lowest values for the mean relative error and standard error of estimate, as well as high values of the coefficient of determination, showing similar adjustment parameters magnitudes. Moreover, only these two models resulted in the average relative error of less than $10 \%$, which was a criterion for model choice in this study.

Therefore, Hukill \& Ives (1955) and Hunter (1983) models are recommended for the representation of static pressure in layers of castor bean grains. In fact, the model proposed by Hukill \& Ives (1955) was recommended by the American Society of Agricultural Engineers (ASAE Standards, 2002) for use in processes that need information about layered static pressure of the most diverse agricultural products. Indeed, we recommend this model for the representation of static pressure in layers of castor bean grains.

The adjusted coefficients of the Hukill \& Ives model (1955) can be used in silo designs for bulk storage of castor bean grains. Furthermore, after measuring the static pressure, an appropriate fan can be selected to allow air to pass through the entire product layer (Araujo Filho \& Zanetti, 2015), thus eliminating the possibility of inappropriate drying and aeration systems designs by using the coefficients of this model estimated for other products.

Figure 5 shows both measured and estimated values of Hukill \& Ives (1955) model of the pressure drop per unit depth of castor bean grains and compared the pressure drop per unit depth of corn and sunflower grains (ASAE Standards, 2002) and dried cherry coffee (Afonso, 1994) estimated by Hukill \& Ives (1955) model. 


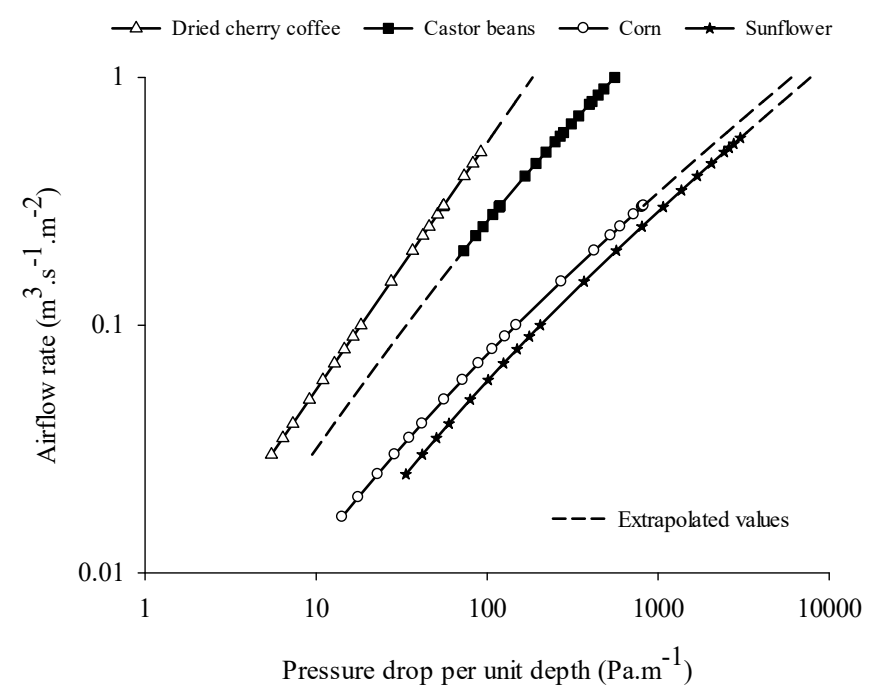

FIGURE 5. Measured and calculated pressure drop per unit depth $\left(\mathrm{Pa} \mathrm{m}^{-1}\right)$ as a function of airflow rate $\left(\mathrm{m}^{3} \mathrm{~s}^{-1} \mathrm{~m}^{-2}\right)$ for castor bean grains compared to other agricultural products.

The slope of the static pressure lines was more pronounced for higher airflow rate values, indicating an increase in pressure in the same position within the grain layer owing to an increased resistance in the air passage. This agrees with data from other agricultural products (Kenghe et al., 2011; Figueiredo Neto et al., 2012; Gratão et al., 2013; Teixeira et al., 2016; Olatunde et al., 2016; Yue \& Zhang 2017).
Furthermore, as depicted in Figure 5, among the analyzed products, only coconut coffee has shown a lower resistance to airflow lower compared to castor bean grains probably because of the greater volume of intergranular spaces of the coconut coffee mass compared to other agricultural products.

For the range of airflow rate used in this work, adding the content of coarse impurities in the castor bean grains layers reduces the resistance to airflow in the bed (Figure 6).

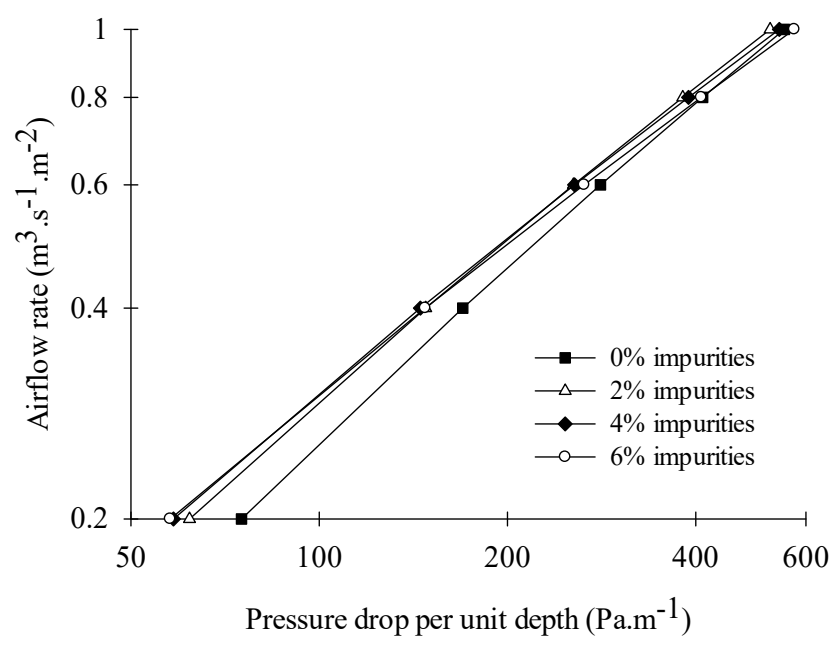

FIGURE 6. Average values of pressure drop per unit depth $\left(\mathrm{Pa} \mathrm{m}^{-1}\right)$ of castor bean grains as a function of airflow rate $\left(\mathrm{m}^{3} \mathrm{~s}^{-1}\right.$ $\mathrm{m}^{-2}$ ) and coarse impurity contents.

As seen in Figure 3b, data can be correlated by increasing the porosity in the castor bean grains layer with the addition of coarse impurities. Air can flow more easily for a greater void volume, thus reducing the loss of load on the layer. These results agree with those obtained by Figueiredo Neto et al. (2012), which studied the effect of different percentages and sizes of impurities on the resistance to airflow in layers of peanut pods. It is also noted that the effect of increasing the percentage of impurities decreases after increasing the airflow in the castor bean grains layer.

Table 3 shows model parameters adjusted to the pressure drop data $\left(\mathrm{Pa} \mathrm{m} \mathrm{m}^{-1}\right)$ of castor bean grains with moisture content of $6 \%$ b.s., depending on airflow rate $\left(\mathrm{m}^{3}\right.$ $\mathrm{s}^{-1} \mathrm{~m}^{-2}$ ) and different levels of impurities, as well as their respective values of standard error of estimate (SSE), mean relative error (MRE), and coefficient of determination $\left(\mathrm{R}^{2}\right)$. 
TABLE 3. Parameter estimations for pressure drop models of castor bean grains with different impurity contents.

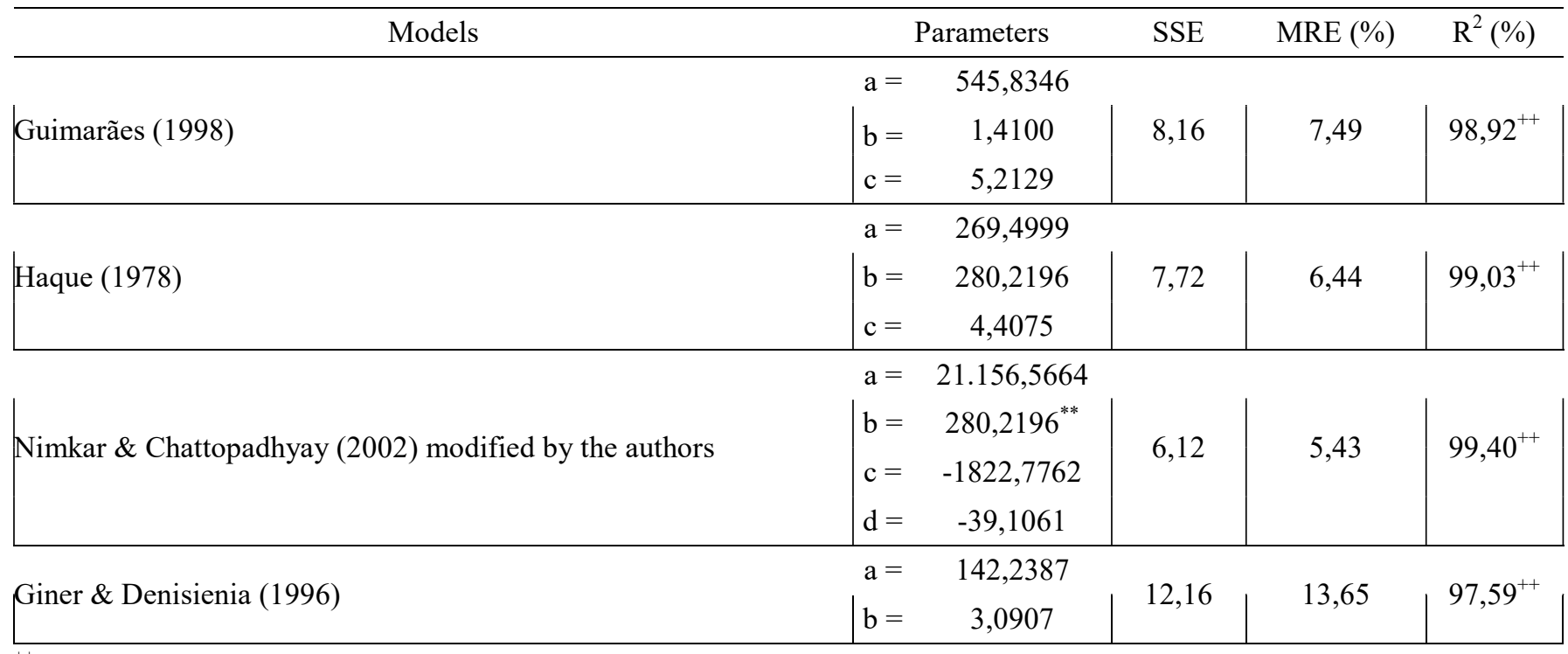

${ }^{++}$Significant at $1 \%$ probability (F-test).

Apart from the model proposed by Giner \& Denisienia (1996), all other adjusted models exhibited reduced values of the mean relative error $(<10 \%)$ and the standard error of estimate, in addition to high values of the determination coefficient, was above 98\%. Among the models that were satisfactorily adjusted to the experimental data, the model proposed by Nimkar \& Chattopadhyay (2002) modified by the authors resulted in the lowest values of the mean relative error and the standard error of estimate, in addition to the highest value of the determination coefficient.

Thus, the modified Nimkar \& Chattopadhyay (2002) model is recommended for evaluating the pressure drop per unit depth of castor bean grains with different coarse impurity contents, as follows:

$$
\Delta \mathrm{PL}=21.156,57 \mathrm{Q}+280,22 \mathrm{Q}^{2}-1.822,78 \mathrm{Q} \mathrm{I}-39,11 \rho_{\mathrm{a}} \mathrm{Q}
$$

The correspondence between the observed values and those estimated by [eq. (11)] (Figure 7) shows a good estimate of pressure drop of castor bean grains in response to airflow rate and impurity content.

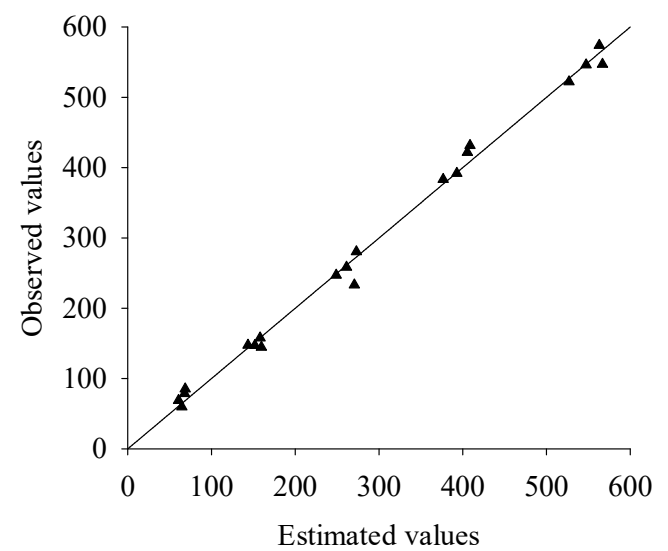

FIGURE 7. Correspondence between the observed and estimated values of pressure drop $\left(\mathrm{Pa} \mathrm{m}^{-1}\right)$ of castor bean grains in response to airflow rate $\left(\mathrm{m}^{3} \mathrm{~s}^{-1} \mathrm{~m}^{-2}\right)$ and coarse impurity contents.

\section{CONCLUSIONS}

Increasing the impurity contents from $0 \%$ to $6 \%$ reduces the static pressure drop of castor bean grains for any airflow rate studied. However, the pressure drop was further influenced by reducing the airflow than by increasing the impurity content.

The model proposed by Hukill \& Ives (1955) is the one that best represents the experimental data of pressure drop per unit depth of castor bean grains, free of impurities, and subjected to airflows rates in the range of 0.2 to $1.0 \mathrm{~m}^{3} \mathrm{~s}^{-1} \mathrm{~m}^{-2}$.

The Nimkar \& Chattopadhyay (2002) model modified by the authors of this work, is the one that best represents the phenomenon of pressure drop for castor bean grains with different coarse impurity content, can be recommended to various applications of preprocessing engineering of this product.

\section{REFERENCES}

Afonso ADL (1994) Static pressure gradient in layers of coffee fruit (Coffea arábica L.) with different moisture content. Dissertation Master's degree, Viçosa, Federal University of Viçosa.

Agullo JO, Marenya MO (2005) Airflow resistance of parchment Arabica coffee. Biosystems Engineering 91(2):149-156.

Araujo Filho JS, Zanetti MG (2015) Use of centrifugal fans in the drying of grains and their dimensioning. Revista de Tecnologias 8(2):50-61.

ASAE Standards (2002) Standards engineering practices data, New York, American Society of Agricultural Enginners, $49^{\text {th }}$ ed. $1041 \mathrm{p}$.

Brasil (2009) Ministry of Agriculture, Livestock and Supply. Rules for seed analysis. Secretariat for Agricultural Defense. Brasília, MAPA/ACS, 399 p. 
Botelho FM, Botelho, SCC, Sobreira MCA (2019)

Influence of impurity contents in physical properties of corn, soybean and rough rice. Scientific Electronic Archives 12(1):52-58.

Botelho FM, Faria BMEM de, Botelho SCC, Martins RN (2018) Methods for grains density determination. Agrarian 11(41):251-259. DOI: http://dx.doi.org/ 10.30612/agrarian.v11i41.7922

Faoro V, Khatchatourian O, Binelo MO, Lima RF (2017) 3D Airflow simulation of a real air system grain storage. Proceeding Series of the Brazilian Society of Applied and Computational Mathematics 5(1). DOI:

https://doi.org/10.5540/03.2017.005.01.0388

Faoro V, Khatchatourian O, Binelo MO, Lima RF (2014) Analysis of air pressure in bulk warehouses through threedimensional airflow simulation. Proceeding Series of the Brazilian Society of Applied and Computational Mathematics 2(1). DOI: http://dx.doi.org/10.5540/03.2014.002.01.0081

Figueiredo Neto A, Dantas BF, Silva JC, Olivier NC, Silva MF (2012) The resistance to the flow of air of the beans of peanut with different percentile of impurity. Nucleus 9(1):85-92.

Giner SA, Denisienia E (1996) Pressure drop through wheat as affected by air velocity, moisture content and fines. Journal of Agricultural Engineering Research 63:73-86.

Goneli ALD, Vieira MDOC, Vilhasanti HCB, Gonçalves AA (2014) Mathematical modeling and effective diffusivity of mastic leaves during drying. Pesquisa Agropecuária Tropical 44(1):56-64. DOI: http://dx.doi.org/10.1590/S1983-40632014000100005

Gratão PTS, Devilla IA, Servulo ACO, Jesus FF, Ferreira DA (2013) Loss of static pressure in a column of quinoa grains. Revista Brasileira de Engenharia Agrícola e Ambiental 17(8):848-854. DOI: http://dx.doi.org/10.1590/S1415-43662013000800008

Guimarães WT (1998) Effect of the level and type of impurities on the resistance to airflow in layers of bean grains (Phaseolus vulgaris L.). Dissertation Master's degree, Viçosa, Federal University of Viçosa.

Haque EG, Foster H, Chung DS, Lai FS (1978) Static pressure drop across a bed of corn mixed with fines. Transactions of the ASAE 21:997-1000.

Hukill WV, Ives NC (1955) Radial airflow resistance of grains. Agricultural Engineering 35:332-335.

Hunter AJ (1983) Pressure difference across an aerated seed bulk for some commun duct and store cross-section. Journal of Agricultural Engineering Research 28:437-450.

Kenghe R, Nimkar P, Shirkole S (2011) Resistance of bulk lathyrus to airflow. Acta Agrophysica 18(1):87-99.
Mata MERMC, Duarte MEM (2002) Agricultural products inter-granular porosity. Revista Brasileira de Produtos Agroindustriais 4(1):79-93.

Mohapatra D, Rao OS (2005) A thin layer drying model of parboiled wheat. Journal of Food Engineering 66:513-518. DOI: http://dx.doi.org/10.1016/j.jfoodeng.2004.04.023

Mohsenin NN (1986) Physical properties of plant and animal materials. New York, Gordon and Breach Publishers, 841p.

Nimkar PM, Chattopadhyay PK (2002) Airflow resistance of greem gram. Biosystems Engineering 82:407-414.

Olatunde G, Atungulu GG, Sadaka S (2016) CFD modeling of airloadflow distribution in rice bin storage system with different grain mass configurations. Biosystems engineering 151:286-297. DOI: http://dx.doi.org/10.1016/j.biosystemseng.2016.09.007

Rampadarath S, Puchooa D (2016) In vitro antimicrobial and larvicidal properties of wild Ricinus communis L. in Mauritius. Asian Pacific Journal of Tropical Biomedicine 6(2):100-107. DOI:

http://dx.doi.org/10.1016/j.apjtb.2015.10.011

Shedd CK (1951) Some new data on resistance of grains to airflow. Agricultural Engineering 32:493-495.

Silva LC (2014) Grain Aeration - Application and Risk. Revista Grãos Brasil: Da Semente ao Consumo 64(1):29-33.

Teixeira DL, Matos AT de, Melo EC (2016) Changes in physical characteristics of organic material submitted to the composting process. Revista Engenharia na Agricultura 24(1):41-49.

Teixeira DL, Matos AT de, Melo EC (2015) Resistance to forced airflow through layers of composting organic material. Waste Management 36:57-62. DOI: http://dx.doi.org/10.1016/j.wasman.2014.12.003

Vasconcellos M (2014) Mathematical modeling of the incidence angle in stored grains. Proceeding Series of the Brazilian Society of Applied and Computational Mathematics 2(1). DOI: https://doi.org/10.5540/03.2014.002.01.0091

Vasconcelos PCT, Loureiro MB, Lima AMMF, Ribeiro PR, Bernal DT, Moreno MLV, Fernandez LG, Castro RD (2017) New insights into the mechanism underlying Ricinus communis L. tolerance to drought stress during germination. Industrial Crops and Products 103:99-106. DOI: https://doi.org/10.1016/j.indcrop.2017.03.038

Yue R, Zhang Q (2017) A pore-scale model for predicting resistance to airflow in bulk grain. Biosystems Engineering, 155:142-151. DOI:

http://dx.doi.org/10.1016/j.biosystemseng.2016.12.007 